\title{
Editorial
}

\section{Hyperlactemia and the Heart}

\author{
Ashima Sharma ${ }^{1} \quad$ Mohammed Ismail Nizami ${ }^{1}$ \\ ${ }^{1}$ Department of Emergency Medicine, Nizam's Institute of Medical \\ Sciences, Hyderabad, Telangana, India
}

Ind J Car Dis Wom 2019;4:66-67

The blood levels of lactates in normal individuals is 0.5 to $1 \mathrm{mmol} / \mathrm{L}$. Disease states cause a mild to moderate increase in lactate concentrations. Values below $2 \mathrm{mmol} / \mathrm{L}$ do not necessitate correction. Persistent rise above 2 to $4 \mathrm{mmol} / \mathrm{L}$ without accompanying metabolic acidosis is referred to as hyperlactemia. Available literature suggests fluid resuscitation and supportive measures to be initiated only if hyperlactemia is associated with acidosis and shock states. Sepsis, septic shock, cardiogenic shock, and hemorrhagic shock are often associated with raised lactates. Hyperlactemia is an independent predictor of death in various categories of critically ill patients. The increase in lactates should not only be linked to hypoperfusion, rather both the production and clearance of lactates should be checked. Tissue substrate requirement, perfusion states, sympathetic activity, endocrine system, certain medications, and hepatic function affect the lactate metabolism.

Lactate is a fuel for myocardium, a source of energy rather than a waste product during strenuous hours. Patients with acute heart failures maintain normal lactates until late in the disease. Anemia, high central venous pressures, and cardiorenal syndrome further contribute to hyperlactemia in these patients. As the failure progresses toward chronicity, patients can have elevated lactates, low mixed venous oxygen saturations without marked arterial oxygen desaturation, and stable hemodynamics. However, this happens in only $25 \%$ of population who are in Stage D of heart failure ${ }^{1}$. Apart from heart failure, lactate has been studied as a prognostication marker for cardiac arrest, acute coronary syndrome, and cardiogenic shock.

In patients with documented lactic acidosis, lactate clearance within a period of 6 hours after the onset of shock is considered to be a better prognostication factor than absolute numerical value of lactate on admission. A decrease in more than $10 \%$ in the value is indicative of adequate fluid resuscitation and high chances of survival. Patients with underlying poor cardiac function are predisposed to pulmonary edema with even small ounces of fluid resuscitation.

There are various ICU scoring systems, for example, sequential organ failure assessment (SOFA), which have been applied to patients for assessing morbidity and mortality in early postoperative period after cardiac surgery. Cardshock score is specifically developed to be used for stratification of patients and prognostication of short-term mortality in patients with cardiogenic shock secondary to medical illnesses. ${ }^{2}$ The score has seven parameters of which serum lactates more than $4 \mathrm{mmol} / \mathrm{L}$ carries the highest individual weightage. The production of lactate in cardiogenic shock is related more to the adrenergic stimulation and oxidative stress than the oxygenation of organs and tissues. ${ }^{3}$

The influence of lactate levels on interventional or diagnostic algorithms in sepsis is extensively studied, very few studies have concentrated on hyperlactemia in patients with poor LV ejection fraction. ${ }^{4}$ We congratulate the authors of the original article titled "Elevated lactate levels as a predictor of early mortality in patients with severe LV dysfunction without shock or hypoxemia" published in this issue on their work on ICCU patients with left ventricular ejection fraction ( LVEF) less than 35\%. They have conducted a retrospective review and identified a blood lactate level $\geq 2.5 \mathrm{mmol} / \mathrm{L}$ as an adjunct negative prognostication marker. Their results are pointing toward a lower ceiling of blood level of lactate in cardiac patients as compared with sepsis patients. Further research is needed to evaluate the effect of lactate clearance on myocardial performance and choice of one therapy over another-initiation of inotrope/vasopressor or fluid resuscitation in similar cohort of patients.

\section{Conflict of Interest}

None.

\footnotetext{
Address for correspondence

Mohammed Ismail Nizami, MD, Department of Emergency Medicine, Nizam's Institute of Medical Sciences, Hyderabad, Telangana 500082, India (e-mail: ismail_nizami@rediffmail.com). published online

September 10, 2019
}

DOI https://doi.org/ 10.1055/s-0039-1697077
CO2019 Women in Cardiology and Related Sciences
License terms

(요 (1) $\Theta \circledast$ 


\section{References}

1 Adamo L, Nassif ME, Novak E, LaRue SJ, Mann DL. Prevalence of lactic acidaemia in patients with advanced heart failure and depressed cardiac output. Eur J Heart Fail 2017;19(8):1027-1033

2 Harjola V-P, Lassus J, Sionis A, et al. CardShock Study Investigators; GREAT network. Clinical picture and risk prediction of short-term mortality in cardiogenic shock. Eur J Heart Fail 2015;17(5):501-509
3 Kubiak GM, Tomasik AR, Bartus K, Olszanecki R, Ceranowicz P. Lactate in cardiogenic shock - current understanding and clinical implications. J Physiol Pharmacol 2018;69(1): $15-21$

4 Lazzeri C, Valente S, Chiostri M, Gensini GF. Clinical significance of lactate in acute cardiac patients. World J Cardiol 2015;7(8):483-489 